\title{
Study of Correlation between High Sensitivity C-Reactive Protein and Serum Uric Acid in Acute Stroke
}

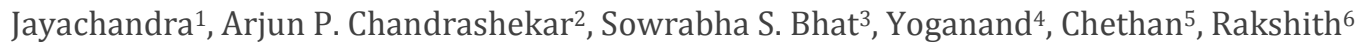 \\ 1, 2, 3, 4, 5, 6 Department of General Medicine, Bangalore Medical College \\ and Research Institute, Bangalore, Karnataka, India.
}

\section{ABSTRACT}

\section{BACKGROUND}

Relationship between serum uric acid and cardiovascular system has been recognised since years. High-sensitivity C-reactive protein (hs-CRP) is a known risk factor for cardiovascular and cerebrovascular events. The role of uric acid as a risk factor for vascular disease and acute stroke is controversial and there is little information about it. ${ }^{1}$ It is unclear as to whether high uric acid concentrations promote or protect against the development of cerebrovascular disease, or simply acts as a passive marker of increased risk. As serum hs-CRP is an established risk factor for stroke, its positive correlation with serum uric acid levels would suggest that high serum uric acid could predict stroke risk. Also, it would prove to be a more cost-effective investigative tool in our present set up.

\section{METHODS}

In this cross-sectional study, we assessed 100 patients admitted with acute stroke in Victoria and Bowring and Lady Curzon Hospital from October 2016 to November 2018. Clinical records, routine investigations, radiological imaging, serum uric acid and hs-CRP of the patients were investigated.

\section{RESULTS}

Majority of the patients (33\%) belonged to the age group of $>70$ yrs., followed by 61 - 70 yrs. (26\%). $69 \%$ of the patients were males and $31 \%$ were females. $67 \%$ of them were hypertensive and $32 \%$ were diabetic. $91 \%$ had an hs-CRP level of $>3.0$ $\mathrm{mg} / \mathrm{L}$ and $8 \%$ had hs-CRP levels between 1.0 and $3.0 \mathrm{mg} / \mathrm{L}$. None of the female patients had a serum uric acid value $>6.5 \mathrm{mg} / \mathrm{dL}$ and none of the male patients had a uric acid level of $>7.0 \mathrm{mg} / \mathrm{dL}$. There was a correlation between serum uric acid levels and serum hs-CRP levels in patients $\leq 50$ yrs. of age. There was no correlation between serum hs-CRP levels and serum uric acid levels in patients more than $50 \mathrm{yrs}$. of age.

\section{CONCLUSIONS}

Our study showed that stroke is most common in persons $>70 \mathrm{yrs}$. of age and is more common in males compared to females. Hypertension is an independent risk factor for stroke. hs-CRP is a well-established risk marker for stroke, being raised in majority of stroke patients. Serum uric acid is not raised in all patients of acute stroke. So, it cannot be used as a risk marker for stroke.

\section{KEY WORDS}

hs-CRP, Serum Uric Acid, Acute Stroke
Corresponding Author: Dr. Arjun P. Chandrashekar, Department of General Medicine, Bangalore Medical College and Research Institute, Bangalore, Karnataka, India. E-mail:arjuhims@gmail.com

DOI: $10.14260 /$ jemds/2021/229

How to Cite This Article: Jayachandra, Chandrashekar AP, Bhat SS, et al. Study of correlation between high sensitivity c-reactive protein and serum uric acid in acute stroke. J Evolution Med Dent Sci 2021;10(15):1074-1078, DOI: 10.14260/jemds/2021/229

Submission 23-06-2020,

Peer Review 12-02-2021,

Acceptance 19-02-2021,

Published 12-04-2021.

Copyright (C) 2021 Jayachandra et al. This is an open access article distributed under Creative Commons Attribution License [Attribution 4.0 International (CC BY 4.0)] 


\section{BACKGROUND}

Cerebrovascular diseases include some of the most common and devastating disorders like ischemic stroke, haemorrhagic stroke, and cerebrovascular anomalies such as intracranial aneurysms and arteriovenous malformations (AVMs). ${ }^{2}$ World Health Organization (WHO) defines stroke as "a rapidly developing clinical symptoms and / or signs of focal (or global) disturbance of brain functions, with symptoms that lasted for 24 hours or more and can cause death, without any other cause other than vascular. ${ }^{3}$

A transient ischemic attack (TIA) is an acute episode of temporary neurologic dysfunction resulting from focal cerebral ischemia not associated with permanent cerebral infarction. Syndrome lasts less than 24 hours. The AHA / ASA defines TIA as follows: Transient ischemic attack is a transient episode of neurological dysfunction caused by focal brain, spinal cord, or retinal ischemia, without acute infarction. ${ }^{4}$ More than $10 \%$ of people who have a TIA will have a stroke within 3 months. Half of these strokes happen during the 48 hours after a TIA. So, a TIA forms the basis for investigating for risk factors and formulate a prevention strategy.

Stroke is the third largest killer in India after heart attack and cancer. A study by the World Health Organisation, which was released in June 2009, says that the incidence of stroke in India is around 130 per 100,000 people every year. In India, nearly 1,000 people succumb to stroke each day, while around 1,500 people live as paralytic throughout their life after they suffer a stroke. The prevalence of stroke in India is estimated to be 55.6 per 100,000 all ages (Dalal 2007).

Risk factors for ischemic stroke are modifiable and nonmodifiable risk factors. Non-modifiable risk factors are age, sex, family history of stroke and race. Modifiable risk factors are hypertension, cardiac disease like atrial fibrillation, diabetes and glucose intolerance, dyslipidaemia, cigarette smoking, alcohol, lifestyle factors like obesity and sedentary lifestyle, asymptomatic carotid stenosis and TIA. Definitive diagnosis is only by.

There is no blood investigation to confirm the diagnosis of stroke. However, some blood tests help in identifying the persons at risk for stroke such as serum hs-CRP, serum homocysteine levels and lipid profile. hs-CRP is a wellconsidered risk factor for cardiovascular events. There are many well-known studies supporting this. Hyperuricemia was associated with cardiovascular disease and hypertension.

Several studies have reported that hyperuricemia is an independent predictor of stroke in diabetic subjects, ${ }^{5}$ individuals with isolated systolic hypertension, ${ }^{6}$ and the general population. Uric acid is quite cheaper and affordable investigation compared to hs-CRP.

\section{Objectives}

- $\quad$ To determine level of serum uric acid levels in patients with acute stroke.

- To determine raised serum hs-CRP levels, an established risk marker, in these stroke patients.

- To find out correlation between raised serum uric acid and hs-CRP levels in these patients.

\section{METHODS}

This cross-sectional study was conducted on 100 stroke patients who were admitted in hospitals attached to Bangalore Medical College and Research Institute. The study was approved by ethics committee and informed consent was obtained. The sample size was taken based on the convenience of the study. History was taken, general physical examination and a detailed systemic examination was done. Routine blood investigations were sent, and a computed tomography (CT) brain was done for all stroke patients to arrive at a definitive diagnosis of infarct or bleed. Serum samples drawn at the time of admission of the patients were sent for estimation of hs-CRP and uric acid levels.

\section{Inclusion Criteria}

Patients diagnosed with stroke within $48 \mathrm{hrs}$. of onset.

\section{Exclusion Criteria}

Patients diagnosed with gout. Patients taking drugs that are known to raise serum uric acid levels like diuretics, chemotherapeutic agents, nicotinic acid, angiotensinconverting enzyme (ACE) inhibitors like losartan. Patients with other recognised risk factors known to increase serum uric acid levels like renal failure, leukaemia, lymphoma, haemolytic anaemia, psoriasis, hypoparathyroidism.

\section{Statistical Analysis}

Descriptive and inferential statistical analysis has been carried out in the present study. Results on continuous measurements are presented on mean \pm SD (min - max) and results on categorical measurements are presented in number (\%). Significance is assessed at $5 \%$ level of significance.

The following assumptions on data were made,

1. Dependent variables should be normally distributed,

2. Samples drawn from the population should be random, cases of the samples should be independent to find the significance of study parameters between three or more groups of patients, Student t-test (two tailed, independent) has been used to find the significance of study parameters on continuous scale between two groups. Inter group analysis is on metric parameters.

The statistical software SAS 9.2, SPSS 15.0, Stata 10.1, MedCalc 9.0.1, Systat 12.0 and R environment ver.2.11.1 were used for the analysis of the data and Microsoft Word and Excel have been used to generate graphs, tables etc.

\section{RESULTS}

In our study majority of the patients (33\%) belonged to the age group of $>70 \mathrm{yrs}$. followed by the age group of $61-70 \mathrm{yrs}$. (26\%). Gender distribution showed majority of patients were males who constituted $69 \%$ and females were $31 \% .67 \%$ were hypertensives and $32 \%$ were diabetics. 


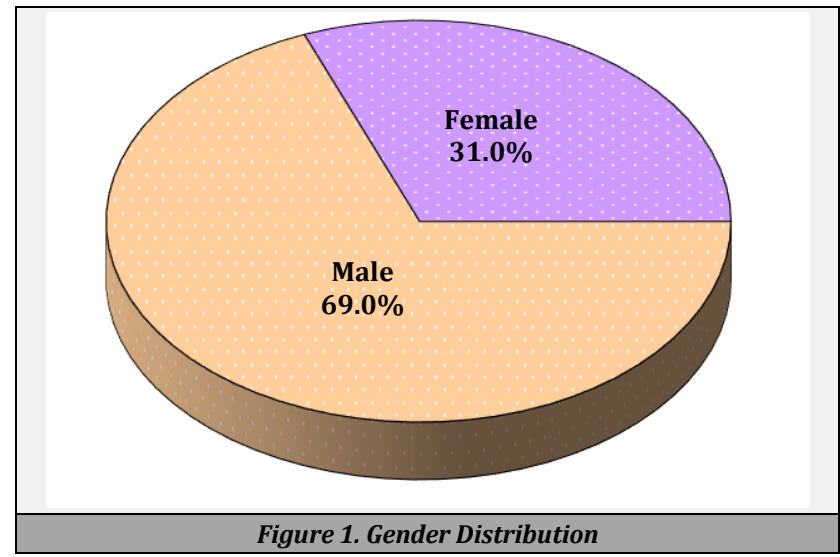

Among the study subjects with cerebrovascular accident, $82 \%$ of the patients presented clinically with hemiparesis and $18 \%$ of the patients presented with hemiplegia. Imaging showed majority of the patients had a middle cerebral artery (MCA) territory infarct on CT brain (35\%) followed by multiinfarct state and internal capsule infarct with $12 \%$ each and basal ganglia bleed (7\%).

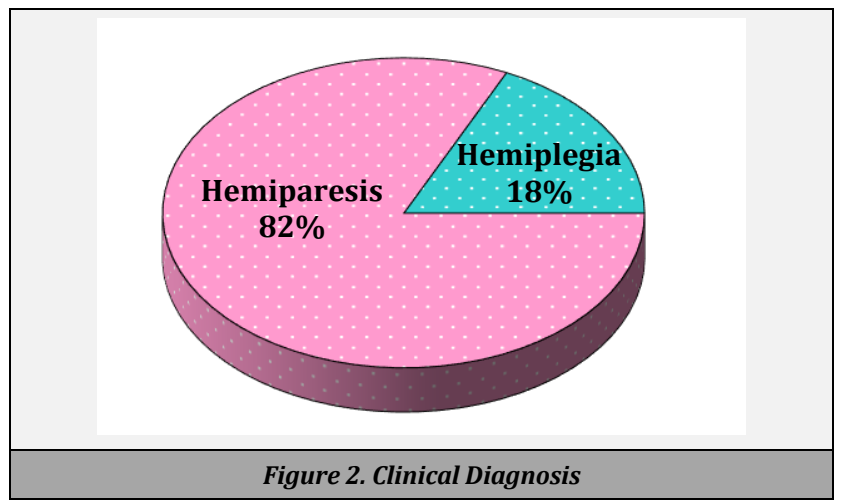

\begin{tabular}{|ccc|}
\hline CT Brain & $\begin{array}{c}\text { Number of Patients } \\
(\mathbf{N}=\mathbf{1 0 0})\end{array}$ & $\mathbf{\%}$ \\
\hline MCA territory infarct & 35 & 35.0 \\
Multi-infarct state & 12 & 12.0 \\
Internal capsule infarct & 12 & 12.0 \\
Basal ganglia bleed & 7 & 7.0 \\
Capsuloganglionic bleed & 6 & 6.0 \\
Putaminal bleed & 6 & 6.0 \\
Temporal lobe infarct & 3 & 3.0 \\
Diffuse cerebral atrophy & 3 & 3.0 \\
Basal ganglia infarct & 3 & 3.0 \\
Capsuloganglionic infarct & 3 & 3.0 \\
Internal capsule bleed & 3 & 3.0 \\
Frontoparietal infarct & 3 & 3.0 \\
Frontal lobe infarct & 2 & 2.0 \\
Normal study & 2 & 2.0 \\
\hline Table 1. Distribution of CT Brain of Patients Studied \\
\hline
\end{tabular}

The mean hs-CRP level was highest in patients in the age group of 61 - 70 yrs. There was no correlation between age of the patients and serum hs-CRP levels.

The mean serum uric acid level was highest in the age group of 61 - 70 yrs, followed by 51 - 60 yrs. The serum uric acid levels increased with increasing age up to $70 \mathrm{yrs}$. In patients above 70 yrs. there was no correlation between age and serum uric acid levels.

The mean hs-CRP level was higher in male patients than female patients. The mean uric acid level was higher in male patients than in female patients.

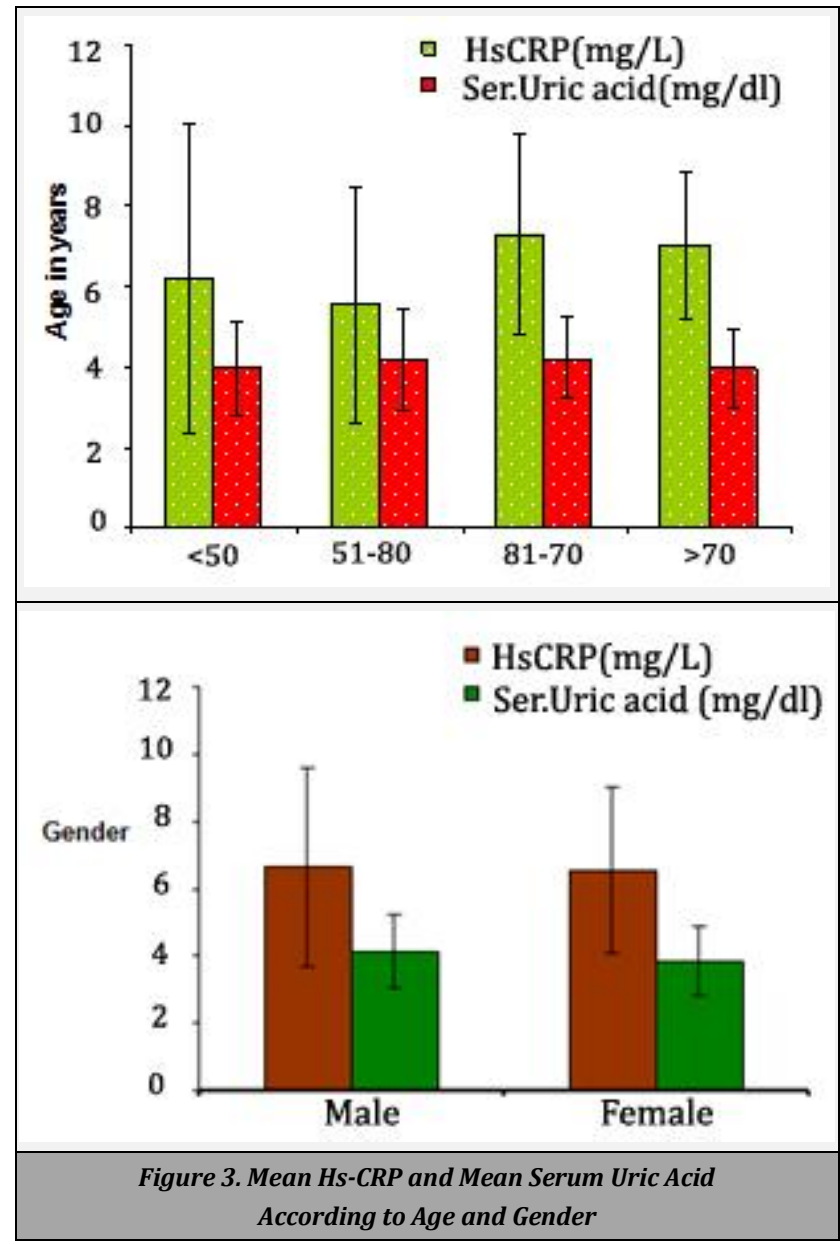

The mean hs-CRP level was lower in hypertensive patients compared to non-hypertensives. The mean uric acid level was higher in hypertensives than in patients without hypertension. The mean hs-CRP level was lower in diabetic patients than in non-diabetics. The mean uric acid level was lower in diabetic patients than in non-diabetics.

The mean hs-CRP level was higher in patients who presented with hemiplegia than in those with hemiparesis. The mean uric acid level was higher in patients with hemiparesis than in those with hemiplegia.

There was a correlation between serum uric acid levels and serum hs-CRP levels in patients $\leq 50 \mathrm{yrs}$. of age. There was no correlation between serum hs-CRP levels and serum uric acid levels in patients more than 50 yrs. of age.

\begin{tabular}{|c|c|c|c|}
\hline & Clinical Diagnosis & $\begin{array}{l}\text { Hs-CRP } \\
\text { (mg / L) }\end{array}$ & $\begin{array}{l}\text { Serum Uric Acid } \\
(\mathrm{mg} / \mathrm{dL})\end{array}$ \\
\hline & Hemiparesis & $6.61 \pm 2.51$ & $4.11 \pm 1.06$ \\
\hline & Hemiplegia & $6.64 \pm 3.95$ & $3.79 \pm 1.14$ \\
\hline & Total & $6.61 \pm 2.80$ & $4.05 \pm 1.08$ \\
\hline & Significantly & $\begin{aligned} \mathrm{t}= & 0.055 ; \mathrm{P}= \\
& 0.957\end{aligned}$ & $\mathrm{t}=1.159 ; \mathrm{P}=0.249$ \\
\hline \multirow{7}{*}{$\begin{array}{l}\text { Correlation of hs-CRP } \\
\text { and serum uric acid } \\
\text { in patients studied }\end{array}$} & Age in Years & \multicolumn{2}{|c|}{$\begin{array}{c}\text { Correlation b / w hs-CRP and Uric } \\
\text { Acid }\end{array}$} \\
\hline & & r Value & P Value \\
\hline & $\leq 50$ & 0.425 & $0.038^{*}$ \\
\hline & $51-60$ & -0.183 & 0.468 \\
\hline & $61-70$ & 0.267 & 0.188 \\
\hline & $>70$ & -0.234 & 0.191 \\
\hline & All cases & 0.116 & 0.249 \\
\hline \multicolumn{4}{|c|}{$\begin{array}{l}\text { Table 2. Mean HS-CRP and Mean Serum Uric Acid } \\
\text { According to Clinical Diagnosis }\end{array}$} \\
\hline
\end{tabular}




\section{DISCUSSION}

In our study majority of the patients belonged to the age group of more than 70 years (33\%). The mean age of the patients was $62.92 \pm 13.01$. In a study by Yue Huang et al, the mean age group of the patients studied was $60.9 \pm 13.3 \mathrm{yrs}^{7}$

In our study majority of the patients were males (69\%) with females constituting $31 \%$. In a study by Yue Huang et al, majority of the patients (74.9\%) were men and $25.1 \%$ were women.

In our study majority of patients had ischemic stroke as per C T brain (73 \%) and $22 \%$ had haemorrhagic stroke. In a study by Giuseppe Seghieri et al. majority of patients had ischemic stroke (81\%) and $19 \%$ had haemorrhagic stroke. ${ }^{8}$

The mean uric acid of the patients in our study was $4.05 \pm$ 1.08 which is within the normal range. In a study by Milionis $\mathrm{H}$ $J$ et al the mean serum uric acid was higher in stroke patients compared to controls. ${ }^{9}$ In a study by Michiel J. Bos et al. there was statistically significant higher serum uric acid value in stroke patients. ${ }^{10}$ In a study by B C Bansal et al., the mean serum uric acid in cases of stroke $(5.8 \mathrm{mg} / \mathrm{dL})$ was higher than that in the controls $(6.5 \mathrm{mg} / \mathrm{dL}$ ) and this difference was statistically significant. ${ }^{11}$

In our study the mean uric acid value increased with age up to 70 years, but this was not statistically significant. In a study by Masoud Mehrpour et al. the mean serum uric acid significantly increased with age of the patient.

In our study $67 \%$ were hypertensives suggesting that it was an independent risk factor for stroke. In a study by Yue Huang et al., $65.4 \%$ of the patients were hypertensives. In our study $32 \%$ of the patients were diabetic. In a study by Yue Huang et al., $27.9 \%$ of the patients were diabetic. ${ }^{8}$

In our study the mean uric acid in males was $4.14 \pm 1.09$ and in females it was $3.85 \pm 1.02$. The mean uric acid was higher in males, but this difference was not statistically significant. In a study by Masoud Mehrpour et al. serum uric acid values were significantly higher in males compared to females. In a study by Michiel J. Bos et al. there was statistically significant difference between mean serum uric acid values in men compared to those in women. ${ }^{12}$ In the study by Angel Chamorro et al. a statistically significantly higher concentration of uric acid was associated with male sex. ${ }^{12}$ In a study by Chih-Cheng Huang et al., mean serum uric acid level was higher in men $(6.893 \pm 1.926 \mathrm{mg} / \mathrm{dL})$ than in women $(5.610 \pm 1.703 \mathrm{mg} / \mathrm{dL}) \cdot{ }^{13}$

In our study mean serum uric acid values were higher in hypertensive patients but this difference was not statistically significant. Whereas in the study by Tushar B Patil et al. there was a statistically significant higher value of uric acid in hypertensives. In a study by Masoud Mehrpour et al. there was no significant correlation between serum uric acid and presence of hypertension. In the study by Angel Chamorro et al. serum uric acid value was higher in hypertensives.

In our study serum uric acid levels were lower in diabetics $(3.88 \pm 0.86)$ than in non-diabetics $(4.13 \pm 1.16)$ but this difference was not significant statistically. In a study by Angel Chamorro et al. serum uric acid was lower in diabetics compared to non-diabetics and this difference was statistically significant.
In our study the mean serum hs-CRP of patients was 6.61 $\pm 2.80 \mathrm{mg}$ / L which was higher than the normal range and this observation was statistically significant. In a study by Seyed Ali Roudbary et al., the mean hs-CRP level of stroke patients was $10.7906 \mathrm{mg} / \mathrm{L} .{ }^{14} \mathrm{In}$ a study by Mitchell S.V. Elkind et al., the mean hs-CRP level of the patients studied was $23.5 \pm 28.4 \mathrm{mg}$ / L.

In our study, serum hs-CRP in ischemic patients was 6.34 \pm 2.42 whereas in haemorrhagic patients it was $6.76 \pm 2.95$ and it was statistically significant. On the contrary, in the study by Seyed Ali Roudbary et al., serum level of hs-CRP in ischemic patients was $18.92 \mathrm{mg} / \mathrm{l}$ and in haemorrhagic group was 2.65 $\mathrm{mg} / \mathrm{dL}$.

This difference was statistically significant that is hs-CRP levels were higher in patients with ischemic stroke. In our study serum hs-CRP levels of the patients did not correlate with their age. In a study by Mitchell S.V. Elkind et al., hs-CRP levels increased with age and the mean level was highest in the patients $>70$ yrs. of age. ${ }^{15}$

\section{CONCLUSIONS}

Our study showed that stroke is most common in persons $>70$ yrs. of age and is more common in males compared to females. Hypertension is an independent risk factor for stroke. hs-CRP is a well-established risk marker for stroke, being raised in majority of stroke patients. Serum uric acid is not raised in all patients of acute stroke. So, it cannot be used as a risk marker for stroke.

Data sharing statement provided by the authors is available with the full text of this article at jemds.com.

Financial or other competing interests: None.

Disclosure forms provided by the authors are available with the full text of this article at jemds.com.

\section{REFERENCES}

[1] Mehrpour M, Khuzan M, Najimi N, et al. Serum uric acid level in acute stroke patients. Medical Journal of the Islamic Republic of Iran 2012;26(2):66-72.

[2] SmithWS. Cerebrovascular diseases. In: Fauci, Kasper, Hauser, eds. Harrison's Principles of Internal Medicine. $20^{\text {th }}$ edn. McGraw-Hill 2018: p. 3068.

[3] Schretlen DJ, Inscore AB, Vannorsdall TD, et al. Serum uric acid and brain ischemia in normal elderly adults. Neurology 2007;69(14):1418-23.

[4] Lehto S, Niskanen L, Rönnemaa T, et al. Serum uric acid is a strong predictor of stroke in patients with non-insulindependent diabetes mellitus. Stroke 1998;29(3):635-9.

[5] Proctor PH. Uric acid: neuroprotective or neurotoxic? Stroke 2008;39(5):e89.

[6] Culleton BF, Larson MG, Kannel WB, et al. Serum uric acid and risk of cardiovascular disease and mortality: The Framingham Heart Study. Ann Intern Med 1999;131(1):7-13.

[7] Huang Y, Jing J, Xing-Quan Z, et al. High-sensitivity Creactive protein is a strong risk factor for death after acute 
ischemic stroke among Chinese. CNS Neuroscience \& Therapeutics 2012;18(3):261-6.

[8] Seghieri G, Moruzzo D, Fascetti S, et al. Increase in serum uric acid is selectively associated with stroke in type 2 diabetes. Diabetes Care 2002;25(6):1095.

[9] Milionis HJ, Kalantzi KJ, Goudevenos JA, et al. Serum uric acid levels and risk for acute ischaemic non-embolic stroke in elderly subjects. J Intern Med 2005;258(5):43541.

[10] Bos MJ, Koudstaal PJ, Hofman A, et al. Uric acid is a risk factor for myocardial infarction and stroke. Stroke 2006;37(6):1503-7.

[11] Bansal BC, Gupta RR, Bansal MR, et al. Serum lipids and uric acid relationship in ischemic thrombotic cerebrovascular disease. Stroke 1975;6:304-7.
[12] Chamorro A, Obach V, Cervera A, et al. Prognostic significance of uric acid serum concentration in patients with acute ischemic stroke. Stroke 2002;33(4):1048-52.

[13] Chih-Cheng H, Ming-Chao P, Wen-Chung T, et al. The serum uric acid and related cardiovascular risk factors in south Taiwan. Southeast Asian J Trop Med Public Health 2005;36(1):259-64.

[14] Roudbary SA, Saadat F, Forghanparast K, et al. Serum Creactive protein level as a biomarker for differentiation of ischemic from hemorrhagic stroke. Acta Medica Iranica 2011;49(3):149-52.

[15] Elkind MSV, Tai W, Coates K, et al. High-sensitivity Creactive protein, lipoprotein-associated phospholipase a2 and outcome after ischemic stroke. Arch Intern Med 2006;166(19):2073-80. 